\title{
EXECUTIVE COMMITTEE WORKING GROUP YOUNG ASTRONOMERS EVENTS
}

\author{
SOC CHAIR \\ MEMBERS
}

LOC CHAIR

\author{
Michèle Gerbaldi \\ Jean-Pierre De Greve, Michal Dovčiak, \\ Oddbjørn Engvold, Edward F. Guinan, \\ John B. Hearnshaw, Melanie Johnston-Hollitt, \\ Jay M. Pasachoff, John R. Percy, \\ Ignasi Ribas, James C. White \\ Michal Dovčiak \\ René Goosmann, Tomáš Pecháček, \\ Ivana Stoklasová
}

\section{PROCEEDINGS IAU XXVI GA YOUNG ASTRONOMERS EVENTS on 15-25 August 2006}

\section{Introduction}

At the IAU XXV General Assembly in Sydney, 2003, a questionnaire on the perception of participation of "young astronomers" at IAU meeting was distributed. Following the conclusions from the analysis of this questionnaire, the IAU EC recommended in 2004 that the "young astronomers" concept at the next GA in Prague should be worked out with specific activities.

After extensive discussions with General Secretary Oddbjørn Engvold, with the IAU Officers during their February 2005 meeting, and with several colleagues involved in Commission 46 programmes, two actions were proposed for the IAU XXVI GA in Prague, 2006, in order to cast light on young astronomers and to create links between the "established" astronomers and the new generation of IAU members.

The proposed actions were $(i)$ a Young Astronomers Lunch Debate, and (ii) a Young Astronomers Consulting Service, as first steps to answer to the concerns expressed by the previous EC:

- to make the IAU better known among the young generation astronomers,

- to identify how the IAU serves and aims to serve the interest of young astronomers,

- to stimulate young astronomers to become actively involved in IAU's programs and activities.

Reciprocally, these actions are a means to alert and educate the IAU itself about its responsibilities for its membership in the broadest sense. These Young Astronomers' Events were primarily organized for astronomers who are enrolled in $\mathrm{PhD}$ programs or who have received their Doctorate degrees within three years before the General Assembly.

Registration to these events was done via the Registration Form for the IAU XXVI GA. Dedicated web pages (<http://astro.cas.cz/yae>) for these events were all created by Dr. Michal Dovčiak. These pages are now available at the URL: <http://www.iau.org> (Commission 46, Astronomy Education \& Development).

The organization and venue of the Young Astronomer Lunch Debate and the Young Astronomers Consulting Service are respectively described in Section 2 and 3. In Section 4 and 5 the analysis of the surveys done on each event are presented. In the conclusion, plans for the future are presented. 


\section{The Young Astronomers Lunch Debate}

The purpose of this luncheon was to give to the young astronomers a splendid opportunity to meet with members of the IAU Executive Committee, representatives from ESA, ESO, NASA and with other participating astronomers in order to exchange ideas and to discuss their research, careers, and educational opportunities for Post-Doctoral positions, as well as employment opportunities.

This luncheon was organized through tables of 11 participants (9 young astronomers +2 guest astronomers), each table discussing one or more topics of interest for young astronomers. The lunch debate took place prior to the Opening Ceremony of the GA on Tuesday August 15th $(11 \mathrm{~h}-13 \mathrm{~h} 30)$. The format selected was a buffet in order to be more flexible according to the different nationalities and diets of the participants.

A questionnaire was prepared in order to select the topics for the table discussions. By the end of June $50 \%$ of the 140 young astronomers, already registered to the lunch debate, answered this questionnaire and a list of topics to be discussed was established. The topics assigned for each table were selected from that list and the young astronomers were asked to register for a table. At the end 177 young astronomers registered and 20 tables were set up, two to three themes being debated at each table.

A difficulty came from the delay between the registration for the IAU XXVI GA, which could have been done as early as March, and the choice of the table and topics associated to it, which was done by the end of June. In July we had to track, by e-mails, the participants to sign up for a table.

A critical point was also the invitation of the guest astronomers, this latter could be done only after a reasonable guess of the number of participants to the lunch. (Annexe 4).

It was planned to record the discussions at each table. Some notes were collected but are difficult to exploit meaningfully. The first feedback of the lunch debate is that the young astronomers were able to start, on the spot, discussions with confirmed astronomers whatever the subject.

Some statistics on the young astronomers who participated to this lunch debate is given in the following tables. Concerning the number of participants per countries, this list is biased because in most of the cases the participants indicated the country where they are doing their studies and not their nationality.

\section{Participants to the Lunch Debate}

156 answers of overall 177 participants

\begin{tabular}{|c|c|c|c|c|}
\hline \multicolumn{5}{|c|}{ Gender: 64 women and 92 men } \\
\hline Situation: & $\begin{array}{c}\text { neither PhD } \\
\text { nor Postdoc } \\
11\end{array}$ & $\begin{array}{l}\mathrm{PhD} \\
\text { only } \\
106\end{array}$ & $\begin{array}{c}\mathrm{PhD} \\
\text { and Postdoc } \\
37\end{array}$ & $\begin{array}{l}\text { Postdoc } \\
\text { only } \\
2\end{array}$ \\
\hline Age group: & $\begin{array}{c}\text { below } 20 \\
3\end{array}$ & $\begin{array}{c}20 \text { to } 24 \\
30\end{array}$ & $\begin{array}{c}25 \text { to } 29 \\
83\end{array}$ & $\begin{array}{cc}30 \text { to } 35 & \text { above } 35 \\
47 & 4\end{array}$ \\
\hline
\end{tabular}


Participants to the Lunch Debate

\begin{tabular}{lclc}
\hline country & $\begin{array}{c}\text { number of } \\
\text { participants }\end{array}$ & $\begin{array}{c}\text { country } \\
\text { participants }\end{array}$ \\
\hline Argentina & 3 & Mexico & 2 \\
Australia & 3 & Morocco & 1 \\
Austria & 1 & Nepal & 1 \\
Brazil & 7 & Netherlands & 5 \\
Canada & 1 & Peru & 2 \\
China & 7 & Poland & 4 \\
China (Taiwan) & 4 & Portugal & 1 \\
Czech Republic & 13 & Romania & 1 \\
Democratic Rep. of Congo & 1 & Russia & 14 \\
Denmark & 1 & Serbia and Montenegro & 4 \\
Egypt & 1 & Slovakia & 2 \\
Estonia & 2 & Slovenia & 1 \\
Finland & 1 & South Africa & 1 \\
France & 6 & South Korea & 1 \\
Germany & 14 & Spain & 10 \\
Greece & 2 & Sweden & 2 \\
Hungary & 1 & Thailand & 1 \\
India & 5 & Turkey & 2 \\
Iran & 3 & United Kingdom & 5 \\
Israel & 2 & Ukraine & 8 \\
Italy & 11 & USA & 16 \\
Japan & 1 & Viet Nam & 1 \\
Macedonia & 1 & & \\
\hline \hline
\end{tabular}

A detailed analysis of the survey on the lunch debate done by Melanie Johnston-Hollitt is presented in Section 4.

\section{Young Astronomers Consulting Service}

The purpose was to have a clearly identified office during the all GA where young astronomers could meet more advanced astronomers to seek advice on their CV, thesis, jobs, etc. during oneto-one personal contacts.

To launch this programme an e-mail was sent to all the already registered astronomers to the GA, by May 2006. In less than two days, more than 80 volunteers expressed their wish to act as a consultant. A consultant database was created with their domains of expertise, as well as a young astronomers' one with their requests. The registration to the Young Astronomers' Consulting Service continued during the all GA.

The arrangement of the one-to-one discussions started before the venue of the GA through the access to the consultants' and/or young astronomers' database, if permitted by the owner of the data. During the GA, the list of potential consultants with their domains of expertise and their consulting hours was put on the notice-board next to the office of the Consulting Service. The young astronomers were then able to sign in for the discussion with a consultant.

A green tag was sticked on the consultants' badge to emphasize their visibility.

Thus the young astronomers could contact the consultants either by signing at the consulting hours form and meet them at the YACS office at the agreed time, or exchange e-mails, or exchange messages through message-box service, or they could approach the consultant directly seeing their green tag.

The Young Astronomers Office was run efficiently by Czech young astronomers - members of the LOC, during the all GA, but its location prevented its direct visibility. 
A report on the run of the Consulting Service during the GA is given by Michal Dovčiak Section 5 .

\section{Report on the survey from the participants to the Lunch Debate}

At the conclusion of the lunch debate, a questionnaire was circulated to all participants and feedback from each table's deliberations was collected. The questions asked and the responses are summarized in Annexes 5 and 6, broken down into responses from young astronomers and guest/senior astronomers respectively.

A total of 149 young astronomers and 18 guests responded to the survey. The responses were overwhelmingly positive and it was clear that the event was a success.

An astounding $98 \%$ of the young astronomers that responded to the question "Do you think the event was a success?" indicated that they did and $92 \%$ indicated that they would like to attend such events in the future (and of the small percentage that did not do it was mostly because they believed they would be "too old" at the next GA).

As a means of facilitating interaction between young and senior astronomers and between young astronomers and their peers the lunch debate was highly successful. $89 \%$ of the young astronomers responded to the question regarding the effectiveness of the event at providing an opportunity to interact with senior astronomers stating it to be effective or very effective and 74 $\%$ believed the event to have also provided an effective or very effective opportunity to interact with their fellow young astronomers.

The topics of the lunch debate were also believed to be well or very well covered by $80 \%$ of respondents. The event also served to increase the sense of partipation for young astronomers with 85 agreeing it had served this purpose for them. Given that one of the major complaints identified in the YA survey during the 2003 GA in Sydney was lack of a sense of participation by young astronomers this is a fantastic result.

Other trends in the data demonstrate the importance of the GA website as a means for promotion of young astronomer activities and there was a strong sense in the comments that the creation of a young astronomer mailing list or other permanent web-based contact resource would be of benefit. It would seem that most participants were happy with the lunch format, but not with the timing of the event which both clashed with interesting scientific sessions and was too early in the program for people only attending the second week of the GA. Additionally, a large number of young astronomers commented that there were too many people per table to provide sufficient interaction with the senior astronomer and that it would have increased the benefit for them had the table sizes been reduced. In future it would be better to have the event in the middle of the GA and might be wise to move to an evening format to avoid clashes.

In summary, it is clear that the lunch debate was an overwhelming success and there is a strong demand from young astronomers for this type of activity to continue at future GAs.

\section{Report on the survey on the Young Astronomers Consulting Service}

Two surveys on the Young Astronomers Consulting Service, hereafter named YACS, were carried out - one assessment questionnaire was for young astronomers and one for consultants.

21 young astronomers filled in the questionnaire out of 145 who have registered for the YACS (Annexe 7). We do not know the exact number of young astronomers that really used this service. This is due to the fact that we tried to make the meetings between young astronomers and consultants as easy to arrange as possible - they could arrange them by exchanging emails or messages in their message boxes, i.e. without coming to the YACS office. 14 consultants answered the assessment questionnaire out of 85 registered consultants (Annexe 8). From the answers to the first question of both questionnaires we estimate that up to 30 or 40 young astronomers addressed up to 20 consultants.

Comments on the YACS were given by both the young astronomers and the consultants.

About $81 \%$ of young astronomers addressed 1 or 2 consultants, $19 \%$ addressed 3 of them. 
About $71 \%$ of consultants were asked for a discussion by 1 or 2 young astronomers and $21 \%$ by 3 young astronomers. We had one very efficient consultant who talked to 7 young astronomers!

The consulting service was very useful in initiating first contacts between young astronomers and consultants. More than $50 \%$ of young astronomers initiated their contact with consultants through the YACS or they saw the green tag on the consultants' badges (given to them by YACS) and contacted them directly. According to consultants even more contacts were established in this way (i.e., with the help of YACS). It seems that the best way to organize meetings was by exchanging e-mails or messages in message boxes between young astronomers and consultants. On the other hand the consulting hours forms were used only in few cases. It was quite difficult for consultants to know and announce their free time slots in advance.

According to $90 \%$ of young astronomers the discussions with consultants were useful and according to $86 \%$ of them the consultant was a suitable person to provide them with the assistance required. $93 \%$ of consultants had the feeling that the discussions were useful for young astronomer. $95 \%$ of young astronomers found the YACS useful, $76 \%$ would use it in the future again and for $90 \%$ of them the participation in this service enhanced their experience of the IAU General Assembly. $24 \%$ of young astronomers thought there were not enough consultants covering a large range of expertise. Approximately half of the young astronomers and half of the consultants made an ongoing link, i.e., expect further contact with each other. $86 \%$ of consultants expressed readiness to be contacted for advice by young astronomers in the period between General Assemblies and $93 \%$ of them are ready to volunteer as a consultant for this service in the future.

$86 \%$ of young astronomers and $64 \%$ of consultants thought it very easy or more-or-less easy to arrange a time and place for the discussions. Most of the discussions took up to 1 hour but there were some of them that lasted even up to 3 hours.

From the above it is quite clear that the service was useful and we think it should be available during next General Assembly as well. Moreover it would be useful to establish some permanent place where young astronomers could find relevant information and ask for advice - this place could be a web page dedicated to young astronomers plus some kind of database of consultants from different countries and research areas who would be willing to help (give a piece of advice via e-mail) even between General Assemblies.

At the end it is needed to emphasize that although only about quarter of the consultants were asked for one-to-one discussion it was very important that so many were accessible. We even advise to encourage more experienced astronomers to register as a consultant during next General Assembly so that there is even better choice in different areas of expertise for young astronomers. There are different opinions on the type of themes that young astronomers wanted to discuss - according to experiences of some of the consultants, young astronomers want to discuss mainly further scientific education and job opportunities. On the other hand some of the young astronomers did not find the right person to talk to because the consultants did not cover enough research fields. This is an interesting question and in future assessment questionnaire it would be good to ask also what types of topics were discussed between young astronomers and consultants.

\section{Closing remarks}

The Young Astronomers Events during the IAU XXVI GA in Prague were a success as indicated by the surveys and informal discussions. We recall three of the answers given by young astronomers concerning the Lunch debate:

- Has the Young Astronomers Events increased your sense of participation at the IAU GA ? yes : $85 \%$

- Effectiveness of providing interaction between young astronomers: effective: $74 \%$

- Effectiveness of providing interaction with senior astronomers: effective : $89 \%$

These Young Astronomers Events should be maintained for the next GA in 2009 with some modifications, the first one is to have the lunch debate later during the first week of the GA, not necessarily the same day as the Opening Ceremony, but still at the beginning of the GA in order to create this special link between the two generations of astronomers as early as possible. 
The lunch debate should be preferably during an evening in order to avoid any overlap with the scientific sessions. The lunch-break is too short to have it in this slot, in the most favorable cases it is one hour.

As many participants are coming to a GA for one week only, several times a second lunch debate, the second week, was mentioned.

If these events are part of the 2009-GA, in Rio, obviously, the team in charge of it should contact Michal Dovčiak (chair of the LOC) as early as possible.

We recommend the creation of a Working Group under the auspice of Commission 46 for a follow-up of the Consulting Service.

The creation of permanent dedicated web pages for the young astronomers with the following suggested topics should be one of the tasks of this Working Group:

- to set up a Consulting Service by e-mail

- to offer selected links to national Young Astronomers (YA) groups, selected links to PhD, PostDoc programmes

- to publicize the offer by Dr. Levato of $5 \%$ of the observing time at the Argentina national observatory El Leoncito $(2.4 \mathrm{~m}$ tel, $0.9 \mathrm{~m}$ tel $)$ for YA through applications and selections.

It can be concluded that the Young Astronomers Events during the IAU XXVI GA organized, for the first time, have fulfilled their role: to facilitate the interactions between the young and the established astronomers and to widely increase the sense of participation of the young astronomers to the GA.

Michèle Gerbaldi

chair of the Working Group 